DOI 10.37882/2223-2966.2020.10.14

\title{
КЛИНИЧЕСКАЯ ХАРАКТЕРИСТИКА КЛИНИКО-ИНСТРУМЕНТАЛЬНОГО ИССЛЕДОВАНИЯ ПАЦИЕНТОВ, ПЕРЕНЕСШИХ ИНФАРКТ МИОКАРДА И СОСТОЯЩИХ НА ДИСПАНСЕРНОМ УЧЕТЕ
}

\section{CLINICAL CHARACTERISTICS OF CLINICAL AND INSTRUMENTAL EXAMINATION OF PATIENTS WHO HAVE HAD MYOCARDIAL INFARCTION AND WHO ARE REGISTERED AT THE DISPENSARY}

\section{Kudaev}

Summary: This paper presents the results of a clinical and instrumental study of patients at the dental clinic of the Federal State Budgetary Educational Establishment "Dagestan State medical University" of the Ministry of Health of the Russian Federation, and the State Budgetary Institution of the Republic of Dagestan "Republican Cardiology Dispension" of the Ministry of Health of the Russian Federation who had myocardial infarction and who are at the dispensary.

Keywords: drug therapy, chronic gastritis, exacerbation, angina pectoris, cardiovascular complications.
Кудаев Джамалудин Магомедович

Ассистент, ФГБОУ ВО «Дагестанский государственный медицинский университет» МЗ РФ dzhamal7676@mail.ru

Аннотация: В настоящей работе представлены результаты клинико-инструментального исследования пациентов стоматологической поликлиники ФГБОУ «Дагмедуниверситет» МЗ РФ, и в Государственное Бюджетное Учреждение республики Дагестан «Республиканский Кардиологический Диспансер» МЗ РФ перенесших инфаркт миокарда и состоящих на диспансерном учете.

Ключевые слова: медикаментозная терапия, хронический гастрит, обострение, стенокардия, сердечно-сосудистые осложнения.
Д ля проверки гипотезы о связи факторов риска ХГП и ИБС, перенесенного ИМ и их значения для развития заболевания [1]. было обследовано 498 нтов, которым была проведена коронарография по поводу ИБС. Больные были консультированы стоматологом на наличие патологии полости рта и им был выставлен диагноз ХГП той или иной степени тяжести. Все пациенты были разделены на группы: 1.213 мужчин, пе-

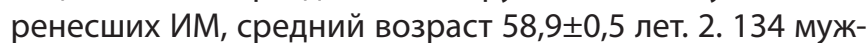

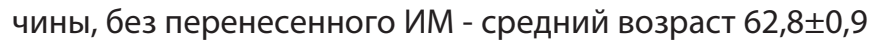
лет. 3. 61 женщина, перенесшая ИМ, средний возраст 59,6 0,7 лет. 4. 90 женщин без перенесенного ИМ, сред-

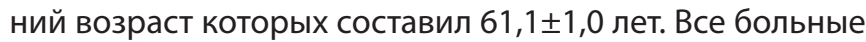
имели стабильную стенокардию налпряжения I-ІІ функционального классов [2], часть пациентов страдала АГ ІІІ стадии, 1-2 степени, риск сердечно-сосудистых осложнений 4 степени [3]. Среди них, мужчины составили 44\%, женщины - 61\%. Сахарный диабет имел место у 16\% мужчин и 38\% женщин. Хронический гастрит вне обострения имел место у $81 \%$ мужчин и $34 \%$ женщин. Медикаментозную терапию клинических проявлений ХГП и ИБС проводили согласно стандартам лечения ХГП [4] и ИБС [2]. Для оценки эффективности влияния препарата Мельдоний на клинико-инструментальные проявления ХГП, путем простой рандомизации были отобраны 140 пациентов: 89 мужчин и 51 женщина, больных ХГП легкой, средней и тяжелой степени, принимавших помимо стандартного лечения ХГП и ИБС, препарат Мельдоний в дозе 250 мг х 2 раза в день в течение 3-х месяцев (основ-

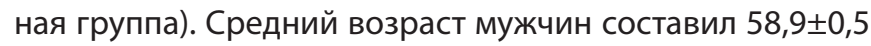

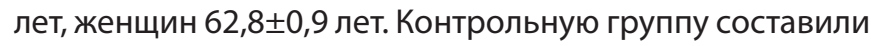
90 пациентов - 55 мужчин, средний возраст 56,8 8 0,5 и 35 женщин, средний возраст 61,4 40,8 лет, перенесших ИМ и имеющих ХГП легкой, средней и тяжелой степени и получавших традиционную терапию ХГП и ИБС. Рандомизация пациентов проходила путем простого подбрасывания игрального кубика. Клинико-инструментальное обследование проводилось до начала приема препарата Мельдоний и через 3 месяца.

Для всех участников исследования являлось обязательным ознакомление и подписание информированного согласия, одобренного в локальном этическом комитете ГБОУ ВПО «Дагестанский государственный медицинский университет» Минздрава РФ. Критериями исключения больных из исследования явились:

1. Наличие: остеопороза, аллергических и инфекционных заболеваний.

2. Проживание в районах экологических, техногенных катастроф, воздействие вредных для организ- 
ма физических, химических факторов.

3. Больные с новообразованиями в анамнезе.

4. Хронический тонзиллит.

5. Прием лекарственных препаратов, влияющих на уровень костной резорбции и гипертрофию десен.

6. Наличие хронических заболеваний в стадии обострения, туберкулез, гепатиты, заболевания крови, системные заболевания соединительной ткани.

7. Полная адентия.

8. Отказ от обследования и лечения.

\section{Методы исследования стоматологического статуса}

1. Клинические методы исследования стоматологического статуса и состояния полости рта пациентов.

2. Индексная оценка состояния пародонта.

3. Ортопародонтография.

4. Реопародонтография.

\section{Методы исследования соматического статуса}

Все больные были обследованы кардиологом, включавшим максимально полный сбор анамнеза и оценку физического статуса. Биохимическое обследование включало анализ крови на холестерин ХС, ТГ, ЛПНП), лПВП, глюкоза крови. Инструментальное исследование включало ЭКГ, ЭХО-КГ. Для определения степени поражения коронарного русла всем больным проводили КАГ с подсчетом КИ. Затем пациенты были обследованы стоматологом с помощью основных и дополнительных методов обследования.

\section{Стоматологическое обследование}

\section{КАинические методы определения состояния паро $\triangle$ онта}

В качестве основополагающих мы приняли документы Комитета экспертов ВО3, касающиеся методов и программ профилактики основных стоматологических заболеваний [1]. Рабочей классификацией болезней пародонта в процессе исследования являлась систематизация, утвержденная на XVI пленуме Правления Всесоюзного общества стоматологов [5].

\section{Методика определения индекса нулкаемости} в лечении заболеваний пародонта (индекс CPITN)

Оценку методики проводили согласно стандартизированным рекомендациям ВО3 [6] с использованием специально разработанного изогнутого зонда, позволяющего измерять глубину десневых карманов. Регистрацию данных по индексу CP1TN проводили по следующим парам признаков-кодов: код СР1TN O - нет патологиче- ских признаков в пародонте; код СР1TN 1 - имеется кровоточивость после зондирования; код CPITN 2 - имеется поддесневой зубной камень; код CPITN 3 - обнаруживается патологический зубодесневой карман глубиной 4-5 мм; код CPITN 4 - выявляется патологический зубодесневой карман глубиной 6 мм и более. Анализ результатов ведется по оценке количества обследованных секстантов зубных дуг, атрибутируемых к определенному коду CPITN, а также по средним величинам CPITN в группах обследованных. Согласно требованиям, обследовали 16 11/21 26, 46 41/ 3136 - состояние секстанта оценивали по зубу, имеющему наихудший индекс. Потребности лечебных мероприятий оценивали параллельно по следующим кодам: код О - лечение не требуется; код 1 - необходимость улучшения гигиены полости рта; коды 2 и 3 - кроме гигиенических мероприятий требуются профессиональная обработка тканей десны и десневых карманов; код 4 - необходимо комплексное пародонтальное лечение с сочетанием различных (хирургических и консервативных) методов лечения.

\section{Методика оченки функшионального состояния сосу ов пародонта}

Реопародонтография является методом для изучения функционального состояния сосудов пародонта, а также прогноза заболевания, оценки эффективности различных способов и средств лечения. Обычно для гингивита и пародонтита характерно снижение эластичности растяжимости сосудистой стенки, уменьшение объемного кровотока, явления застоя в венозном русле, а на более поздних стадиях - органические изменения в стенках сосудов. Кровоснабжение тканей пародонта исследовали с помощью реопародонтографии. Реопародонтография (РПГ) - это графическая запись пульсовых колебаний комплексного сопротивления (импеданса) тканей при прохождении через них высокочастотного тока. Эти колебания отражают функциональное состояние регионарных сосудов. Для проведения РПГ нами использовалась серийная аппаратура: реоплетизмограф РПГ-203 (рабочая частота 100 кГц), усилитель биопотенциалов УБФ-4-03, компьютер со специальным программным обеспечением. Электродную систему, состоящую 53 из 4-х электродных пластинок размером 3х4 мм, укрепленных на хлорвиниловой полоске размером 4×30 мм, накладывали на слизистую оболочку альвеолярного отростка и фиксировали на коже щеки лейкопластырем. Исследование кровоснабжения пародонта на верхней и нижней челюстях проводили в области фронтальных зубов и электродную систему устанавливали от клыка до клыка. Для выявления функциональных и структурных изменений в сосудах пародонта регистрировали реограммы указательного пальца, с которым сравнивали фоновые РПГ. После полученных данных проводили расшифровку и анализ РПГ визуально и по количественным показателям. Количественные показатели оценивали 
следующим образом: вазодилятацию характеризуют показатели ПТС (показатель тонус сосудов) ниже 13\%; ИПС (индекс периферического сопротивления) ниже 80\%; ИЭ (индекс эластичности) выше 80\%. Вазоконструкцию характеризуют показатели ПТС выше 15\%, ИПС - выше 90\%, ИЭ - ниже 70\%

\section{Аополнительные методы стоматологического обследования - Рентгенологическое исследование}

Всем пациентам выполнялась ортопантомография (для общей картины состояния костной ткани челюстей, твёрдых тканей зубов). С помощью ортопантомограммы выявляли наличие разрушения альвеолярной костной ткани, апикальную деструкцию, качество эндодонтического лечения, наличие нависающих краёв пломб, коронок, поддесневого камня и изменений твёрдых тканей зуба. С помощью прицельных дентальных снимков в дополнение к результатам зондирования определяли степень распространения деструкции альвеолярной костной ткани и поражений на участке фуркации корней. Степень деструкции описывали как одну из трёх степеней тяжести процесса: начальную среднюю и развивающуюся. При этом начальная стадия характеризовалась нарушением чёткости строения вершин межальвеолярных перегородок, без уменьшения их высоты и при отсутствии компактной замыкательной пластинки, наличии расширения периодонтальной щели в пришеечной области и убыль костной ткани на 1/3 - 1-степень, на 2/3 - 2-ястепень и при полном исчезновении костной ткани 3-я. Также определялся вид деструкции костной ткани (горизонтальная или вертикальная резорбция кости альвеолярного отростка).

\section{Биохимические исследования крови}

Всем больным проводились биохимические исследования крови на ХС, ЛПНП, ЛПВП, ТГ, глюкозу по общепринятым методикам с использованием лабораторного оборудования.

\section{Электрокарциография}

ЭКГ-исследование больным проводили с использованием следующих приборов: «Mingograf» фирмы «Siemens» (Швеция). Записывали 3 стандартные отведения, Ш-е стандартное отведение на вдохе, 3 усиленных отведения от конечностей и 6 грудных.

\section{Эхокардиографическое исследование}

Эхокардиографическое исследование (ЭхоКГ) проводили по стандартной методике в положении пациента на левом боку из апикального доступа на аппарате «HewlettPackard»Sonos7500 (США) фазово- электронным датчиком с частотой 1.8-4 Мгц. «Sim - 5000 Plus» (Italy) [8]. Определяли следующие показатели: для подтверждения наличия гипертрофии левого желудочка определяли: толщина в диастолу межжелудочковой перегородки и задней стенки ТМЖП и ТЗСЛЖ в сантиметрах. Кроме того, определяли наличие гипо- или акинезастенок миокарда свидетельствующих о перенесенном инфаркте миокарда.

\section{Коронароангиография}

Исследование проводили всем пациентам, включенным в исследование по стандартной методике Сельдингера с лучевым или паховым доступом [7]. Проводился подсчет количества коронарных артерий с атеросклеротической обструкцией более $60 \%$. Каждая артерия с поражением более 60\% принималась за единицу, по сумме пораженных артерий вычислялся коронарный индекс (КИ).

\section{Статистическая обработка результатов исслеАования}

Для оперативной обработки значительных объемов клинико-диагностической информации, полученной в результате исследований, в работе была использована статистическая обработка, которую осуществляли при помощи стандартных методов математической статистики. Достоверность результатов оценивали согласно $\mathrm{t}$ - критерию Стьюдента по следующей схеме: вычисляли значения среднего арифметического - М, стандартного отклонения - $\mathbf{m}$ и коэффициента Стьюдента t по формуле:

$$
t=\frac{M_{1}-M_{2}}{\sqrt{m_{1}^{2}+m_{2}^{2}}}
$$

За достоверную разницу принимали значения $\mathrm{p}<0,05$.

Собранные нами базы данных, содержащие информацию о характеристике больных и результатах исследований, подвергались статистической обработке с помощью пакетов STATGRAPHICS и STATISTICA FOR WINDOWS. Для построения графиков и рисунков использовался пакет MICROSOFT GRAPH. В качестве текстового редактора использовался пакет MICROSOFT WORD. B процессе статистической обработки определяли соответствие изучаемых показателей нормальному распределению. Вычислялись среднее арифметическое, среднее квадратическое отклонения, стандартная ошибка, асимметрия, коэффициенты корреляции Пирсона и Спирмена. Рассчитывались абсолютные и относительные разности ряда динамических, показателей, а также вышеуказанные параметры для абсолютных и относительных разностей.

Статистические гипотезы при сравнении выборок в условиях нормального распределения проверялись с 
помощью t-критерия Стьюдента, парного критерия Стьюдента, а в других случаях - с помощью точного критерия Фишера, критерия Колмогорова-Смирнова и других непараметрических критериев. При сравнении долевого распределения показателей использовался критерий \%2, а при сравнении средних показателей в группах, различающихся по какому-либо признаку, - однофакторный дис- персионный анализ. Корреляционный и регрессионный анализ проводился на основе ряда специализированных пакетов по обработке статистической информации на порядковых, ранговых и номинальных шкалах. Статистически достоверными считались корреляционные коэффициенты, превышавшие 0,30 по абсолютной величине [9].

\section{ЛИТЕРАТУРА}

1. Руководство по методам регистрации стоматологического статуса населения. В03, Женева, «ММСИ», 1995, - 28 с.

2. Рекомендации по лечению стабильной ишемической болезни сердца. Российский кардиологический журнал. №7(111) 2014.

3. Рекомендации по лечению артериальной гипертонии. ESH/ESC 2013 C.15-38.

4. Клинические рекомендации (протоколы лечения) при диагнозе пародонтит. Утверждены Решением Совета Ассоциации общественных объединений «Стоматологическая Ассоциация России» 23 апреля 2013 года с изменениями и дополнениями на основании Постановления № 18 Совета Ассоциации общественных объединений «Стоматологическая Ассоциация России» от 30 сентября 2014 года.

5. XVI Пленум правления Всесоюзн. науч. общества стоматологов // Стоматология, №4, 1984, - c. 4-5.

6. В03: Стоматологические обследования. Основные методы. 4-е изд-е, В03: Женева, 1997,-76 с.

7. Афанасьева, У. В. Роль микробного фактора в развитии начальных форм воспалительных заболеваний пародонта / У. В. Афанасьева, А. М. Соловьева, Г. Е. Афиногенов // Клиническая имплантология и стоматология. - 2001. - № 3-4. - С. 81-84.

8. Шиллер Н. Клиническая эхокардиография / Н. Шиллер, М.А. Осипов // М., Медицина, 1993, - 347 с.

9. Гублер Е.В. Применение непараметрических критериев статистики в медико-биологических исследованиях / Е.В. Гублер, А.А. Генкин // Л., Медицина, 1973,-с. 19-21.

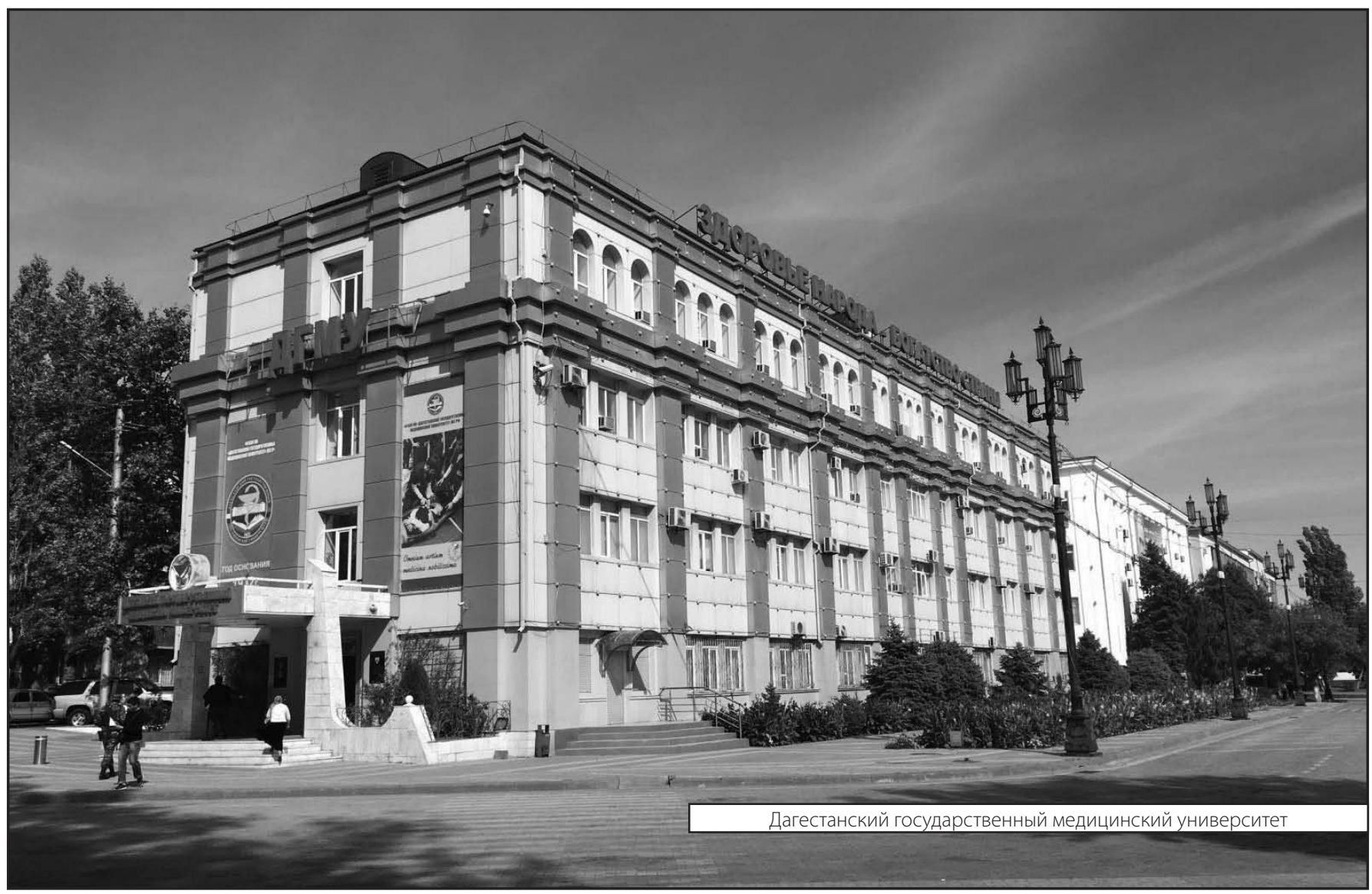

